\title{
Millimeter-Wave Mobile Communications Microstrip Antenna for 5G - A Future Antenna
}

\author{
Brajlata Chauhan \\ Assistant Professor \\ DIT University \\ Dehradun
}

\author{
Sandip Vijay \\ Professor \\ DIT University \\ Dehradun
}

\author{
S.C. Gupta \\ Professor \\ DIT University \\ Dehradun
}

\begin{abstract}
In the present scenario, cellular service provider facing bandwidth shortage in conventional cellular system, and delivering high quality, low latency video and multimedia applications using $3 \mathrm{G}$ system which is on ground .The $4^{\text {th }}$ Generation cellular networks are expected to be implemented in next few years. Here, we present the motivational approach for millimeter wave mobile communication antenna for nextgeneration micro- and Pico-cellular wireless Networks $\left(5^{\text {th }}\right.$ generation). The Millimeter Wave mobile communication works on $28 \mathrm{GHz}$ and $38 \mathrm{GHz}$ frequency by employing steerable directional antennas (high dimensional antenna array) at base stations and mobile devices [1].

This paper describes a future antenna for $5 \mathrm{G}$ mobile communication. This antenna consists of two rectangular patch elements using a single layer RT/Duroid 5880 substrate with transformer coupled impedance matching network, which provides high gain of $9.0583 \mathrm{~dB}$ and efficiency $83.308 \%$. This antenna has good performance in terms of antenna gain, directivity, return losses, VSWR, Characteristics impedance, Band width and efficiency at the centre frequency $38 \mathrm{GHz}$.
\end{abstract}

\section{Keywords}

RMPA，28GHz，38GHz，5G， Mobile Communication, Directional Antenna, ADS-2009, Impedance matching

\section{INTRODUCTION}

Mobile and wireless communication networks (GSM,2G, $2.5 \mathrm{G}, 3 \mathrm{G}$ ) have made tremendous growth in the last fifteen years. The multimedia application for cellular system are limited to carrier frequency spectrum between $700 \mathrm{MHz} \&$ 2.6Ghz.The global spectrum bandwidth allocation for all the cellular networks does not exceed $780 \mathrm{MHz}$ where each Service provider has approximately $200 \mathrm{MHz}$ across all of the different cellular bands of the available spectrum[2]. This millimeter wave research done in the urban environments around the University of Texas at Austin $(38 \mathrm{GHz}$ ) and New York University $(28 \mathrm{GHz})$.

For the bandwidth aspects, here millimeter wave mobile communications technique is introduced and a micro-strip antenna has developed for 5G cellular network/device. Regarding the $4 \mathrm{G}$ and $5 \mathrm{G}$, its focus is towards seamless integration of cellular networks such as GSM and 3G, WLAN and Bluetooth [4]

Micro-strip patch antenna (MPAs) has attractive and widespread features due to its low profile, small size, light weight, low cost as well as to the fact these are very simple to design, suited to planer and non-planer surfaces. However their further use in specific systems is limited of their relatively narrow bandwidth. The principle of wide bandwidth or bandwidth enhancement of MPAs may be achieved by several

Efficient approaches such as: Increasing the substrate thickness, Optimizing impedance matching, Reduce substrate effective permittivity, incorporating multiple resonances.

\section{CONFIGURATION OF PROPOSED MICROSTRIP ANTENNA ARRAY}

The proposed antenna array $1 \times 1$ consist of a Rectangular radiating series feed element printed on one side of dielectric substrate with a ground plane on the other side of it [3]. Due to the absence of the top ground plate and the dielectric substrate above the strip, the electric field lines remain partially in the air and partially in the lower dielectric substrate. This makes the mode of propagation not pure TEM but that is quasi-TEM. Due to the open structure and any presence in discontinuity, the micro-strip line radiates electromagnetic energy. The use of thin and high dielectric materials reduces the radiation loss of the open structure where the fields are mostly confined inside the dielectric.

Any transmission line system which is filled with a uniform dielectric can support a single well defined mode of propagation at least over a specific range of frequencies (TEM for coaxial lines TE or TM for wave guides.) Transmission lines which do not have such a uniform dielectric filling cannot support a single mode of propagation. Micro-strip falls $[7,8]$ in this category. Here the bulk of energy is transmitted along the micro-strip with a field distribution which quite closely resembles TEM and is usually referred to as Quasi TEM.

\section{DESIGN METHODOLOGY FOR PROPOSED ANTENNA}

The basic micro-strip transmission line methodology (formulas) and line calculation analyze from ADS, used for the designing of MPAA. The micro-strip design consists of finding the values of width (w) and length (l) corresponding to the characteristic impendence $\left(\mathrm{Z}_{\mathrm{o}}\right)$ defined at the design stage of the network. A substrate of permittivity ( $(\mathrm{r})$ and thickness (h) is chosen $[3,6,12]$. The effective micro-strip permittivity $\left(\epsilon_{\mathrm{eff}}\right)$ is unique to a fixed dielectric transmission line system and provides a useful link between various wave lengths impedances and velocities. The micro-strip in general, will have a finite strip thickness ' $t$ ' which influences the field distribution for moderate power applications. The thickness of the conducting strip is quite significant when considering conductor losses [8]. But at smaller values of $\mathrm{w} / \mathrm{h}$ or greater values of $\mathrm{t} / \mathrm{h}$, the significance increases. 


\subsection{Line Calculation}

Line calculation for Patch in terms of length L, Width W, Height $\mathrm{H}$, and characteristics impedance $\mathrm{Z}_{0}$ at centre frequency $38 \mathrm{GHz}$ can be calculated by following calculation and optimized by ADS.

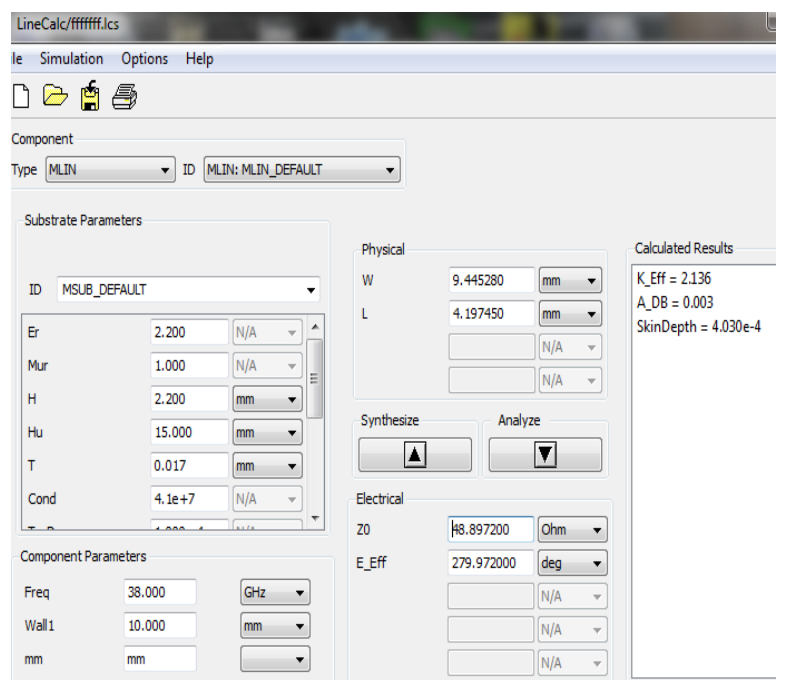

Fig.1 Line Calculation Using ADS

The initial design was done by hand to create a rough model in which to begin simulations. The equations are as listed below and sourced by:

$\varepsilon_{\text {eff }}=(\varepsilon r+1) / 2+(\varepsilon r-1) / 2[1+12(h / W))^{-1 / 2}$

$\mathrm{L}=0.814 \mathrm{~h}\left(\varepsilon_{\text {eff }}+0.3\right)(\mathrm{W} / \mathrm{h}+0.264) /\left\{\left(\varepsilon_{\text {eff }}-0.258\right)(\mathrm{W} / \mathrm{h}+\right.$

$0.8)\}$

$\mathrm{W}=0.5 \lambda 0 / \sqrt{ }\left(\varepsilon_{\text {reff }}+1\right) / 2$

Characteristics impedance $\mathrm{Z}_{0}$ are as:

When $\mathrm{W} / \mathrm{H} \geq 1$

$\mathrm{Z}_{0}=120 \pi / \sqrt{ }\left(\varepsilon_{\text {reff }}[(\mathrm{W} / \mathrm{H})+1.393+2 / 3 \ln \{(\mathrm{W} / \mathrm{H})+1.444\}]\right.$

Due to fringing fields, the change in dimensions of length is given by:

\begin{tabular}{|c|c|}
\hline$\Delta \mathrm{L}=\underline{0.412 \mathrm{~h}}$ & $+0.3) *\{(\mathrm{~W} / \mathrm{H})+0.264$ \\
\hline & $.258) *\{(\mathrm{~W} / \mathrm{H})+0.8\}]$ \\
\hline Effective len & eff $=\mathrm{L}+2 \Delta \mathrm{L}$ \\
\hline Patch Width & $=7.142 \mathrm{~mm}$ \\
\hline Length & $=4.31$ \\
\hline Height & $=2.12 \mathrm{~mm}$ \\
\hline Dielectric & $=2.2$ \\
\hline Total Height & $=12 \mathrm{~mm}$ \\
\hline $\mathrm{Z}_{\mathrm{o}}$ & $=48.4 \mathrm{ohm}$ \\
\hline Centre freque & $=38 \mathrm{GHz}$ \\
\hline
\end{tabular}

\subsection{Radiation Mechanism and Antenna Structure}

The radiation pattern and the input impedance are determined by solving Maxwell's equations for a given antenna structure .Depending upon the solution technique taken, either an integral or differential form of Maxwell's equations in frequencies domain, or time domain is selected to prescribe the problem. Sometimes, a combination of equations forms or domain is used to describe complex antenna problems. These equations are solved using various numerical methods available such as, the integral form of Maxwell's which are solved using the Method of moments (MoM)[7] and other popular techniques include the finite element method and finite-difference time-domain method (FDTD) $[8,9]$.

The layout of optimized array has been designed by using thick of $2.124 \mathrm{~mm}$ RT/Duroid substrate. The geometry of proposed antenna $1 \times 1$ array shown in fig. 1 Its characteristic parameters length $\mathrm{L}$, width $\mathrm{W}$, and thickness $\mathrm{h}$ to meet the design requirements of antenna array, various analytical approaches may be used. The used calculations are based on transmission line model [3, 6, 11].

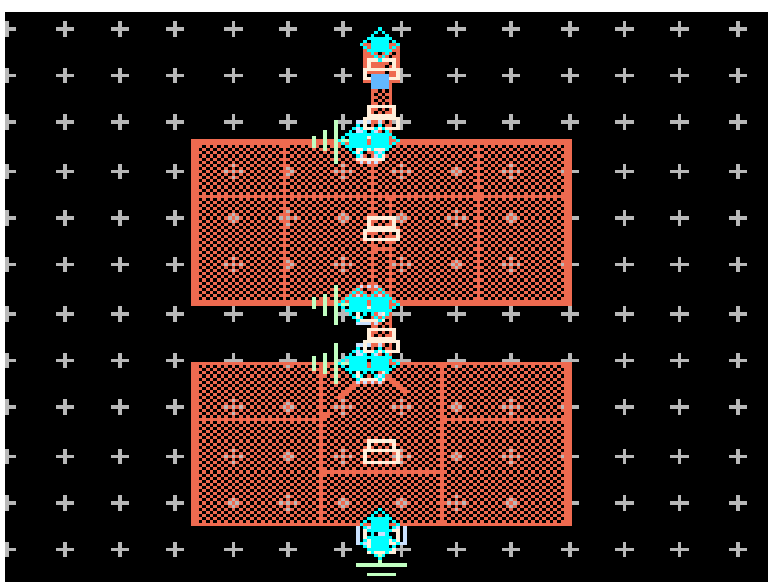

Fig.2. layout of $1 \times 1$ element antenna

\section{SIMULATION AND RESULT ANALYSIS}

Principle of operation of ADS momentum based on MoM Method of moment .Simulation of s -parameter and by clicking radiation pattern in 2-D \&3-D radiation patterns has been obtained .This gives all antenna parameter such as Radiation pattern, Gain, Directivity, Radiate power, Effective angle, maximum intensity etc.

\subsection{S11 Parameters}

In this design, input reflection coefficients or the S11 parameter for the antenna element is $-42.78 \mathrm{~dB}$ at resonant frequency $38.11 \mathrm{GHz}$. At the resonant frequency the input reflection coefficient has the minimum magnitude which is about $-42.78 \mathrm{~dB}$. The input reflection coefficient is shown in figure 3-4 on the Smith chart where the marker clearly indicates that the micro-strip array antenna resonates at 38 $\mathrm{GHz}$ having the minimum impedance $(1.011+\mathrm{j} 0.12)$ over the straight resistance line at the resonating frequency. VSWR for this antenna is 1.089 ; the graphs in the above figures verify the performance of the designed antenna to a great extent.

\subsection{Gain, Bandwidth, Directivity and Efficiency}

The proposed design excited in its fundamental mode has a maximum directivity in the direction perpendicular to the patch (broadside). The peak Gain 9.025 dB and Directivity 10.0336dB are obtained by electric field radiation pattern of array in 3-D analysis of ADS software. And the maximum $10 \mathrm{~dB}$ bandwidth of $1.27 \mathrm{GHz}$ has been achieved in simulation of $\mathrm{S}_{11}$ parameter for frequency band $37.56-38.83 \mathrm{GHz}$ shown in figure 6 . 


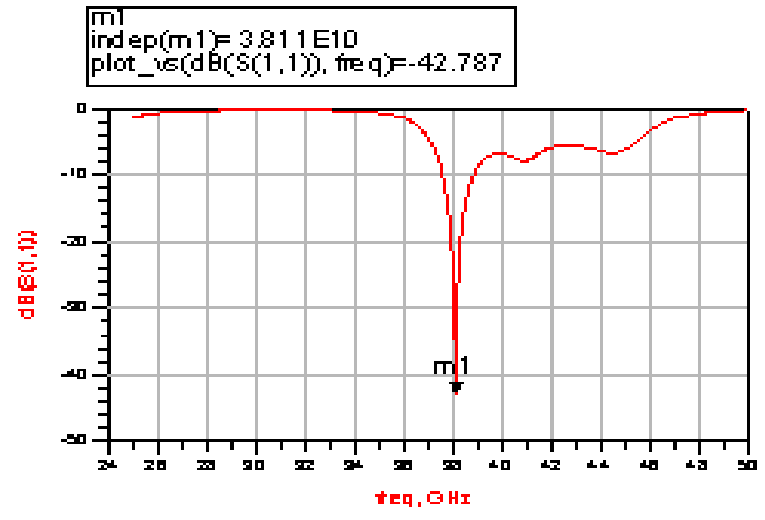

Fig.3. Return loss $-42.787 \mathrm{~dB}$ at $38.11 \mathrm{GHz}$

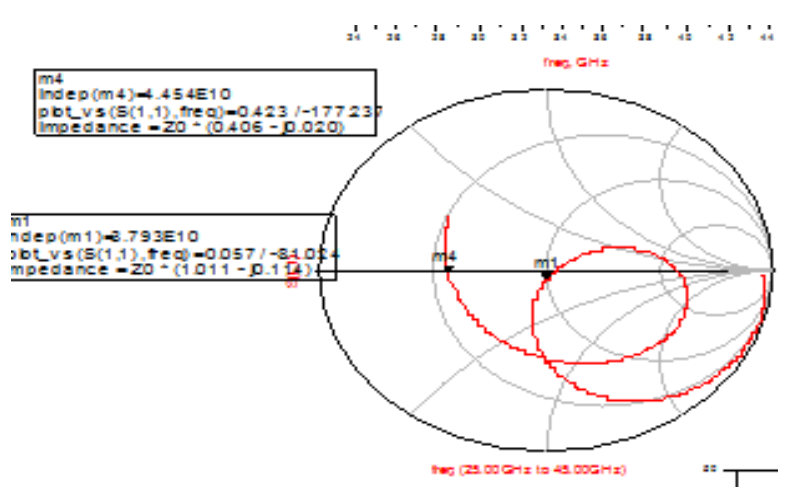

Fig.4. Smith Chart-Characteristics impedance 1.011-j0.12 $\Omega$ at $37.93 \mathrm{GHz}$

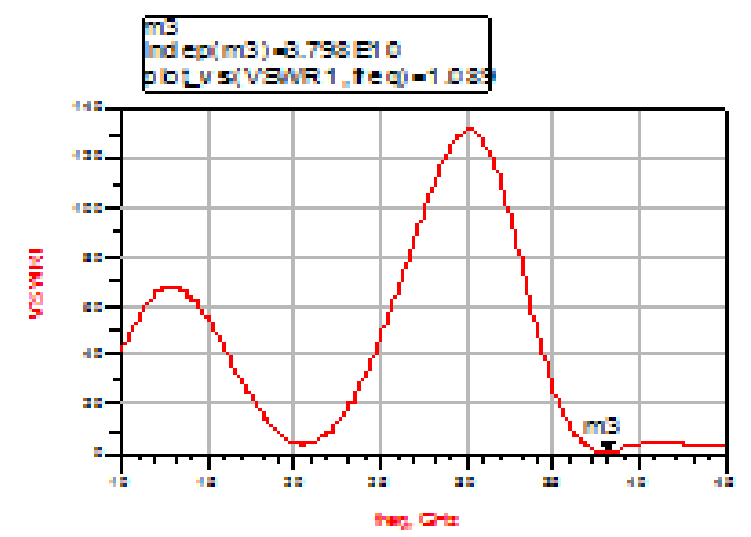

Fig.5.VSWR1.089 at 37.93GHz

The efficiency of the antenna array is shown by 2-D analysis of ADS in the fig.7. The efficiency of antenna array is far better than the efficiency of single patch antenna. The efficiency of the $1 \times 1$ array antenna is $88.361 \%$ while the efficiency of single element was $77.63 \%$ shows an accurate three dimensional graph of the radiation pattern of the microstrip patch array antenna. The antenna is radiating broadside i.e. Perpendicular to the axis of the patch. The main beam is sharp in between $90^{\circ}$ and $270^{\circ}$. This graph shows that the design is working well and that it has achieved the desired results. A more advanced 3D curve is obtained from the ADS Momentum using a feature called the Electro Magnetic Design Solver showing a different presentation method of the
3D curves. The Graph obtained by EMDS is shown in figure for two array.

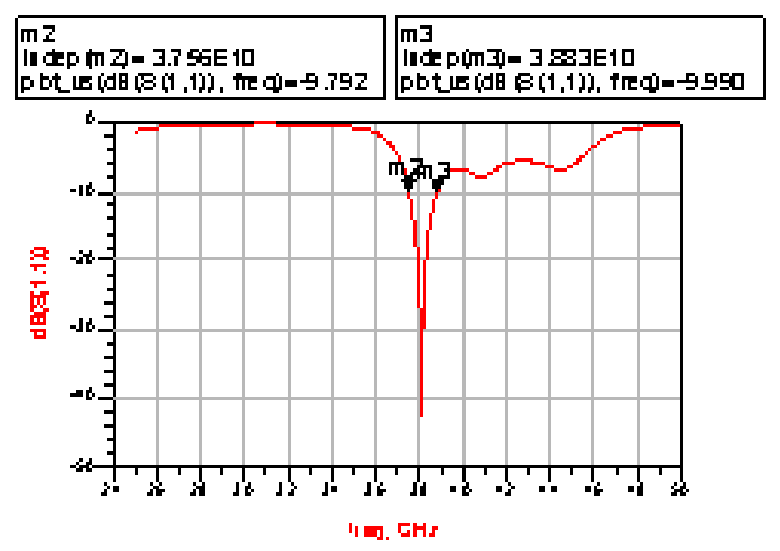

Fig.6. Bandwidth-10 dB lower frequency at $37.56 \mathrm{GHz}$ and Higher frequency at $38.83 \mathrm{GHz}$

$\mathrm{BW}=\frac{\{(\mathrm{FH}-\mathrm{FL}) \times 100\}}{\mathrm{F} 0}$

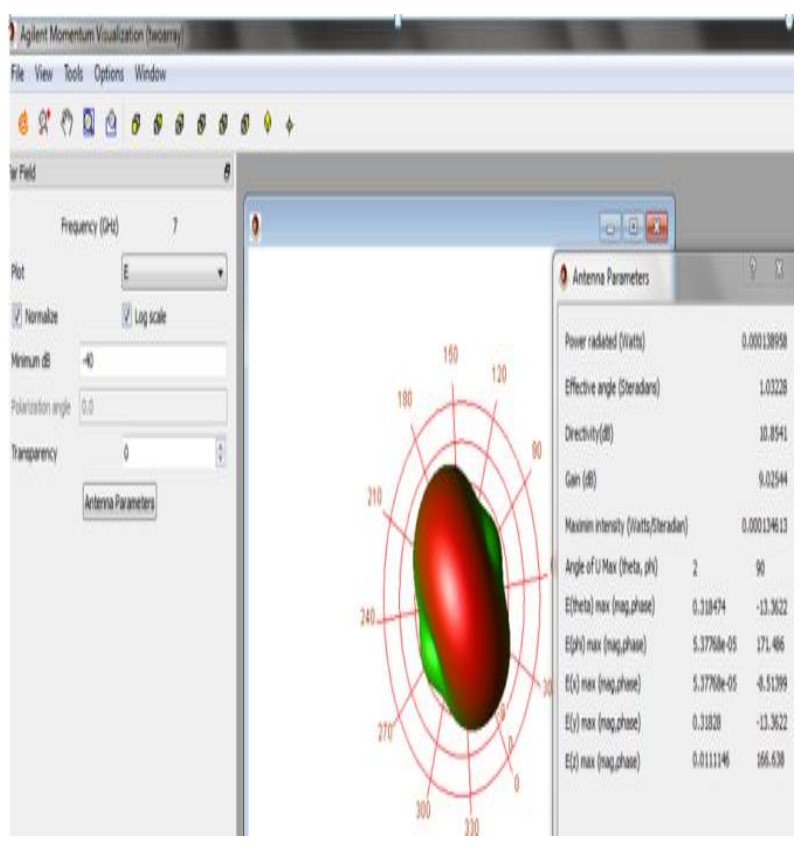

Fig.7. Antenna parameter and radiation pattern in 3-D

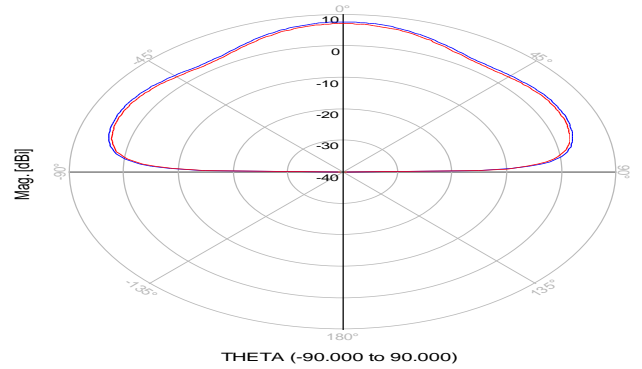

Fig.8. Power Analysis of Antenna 


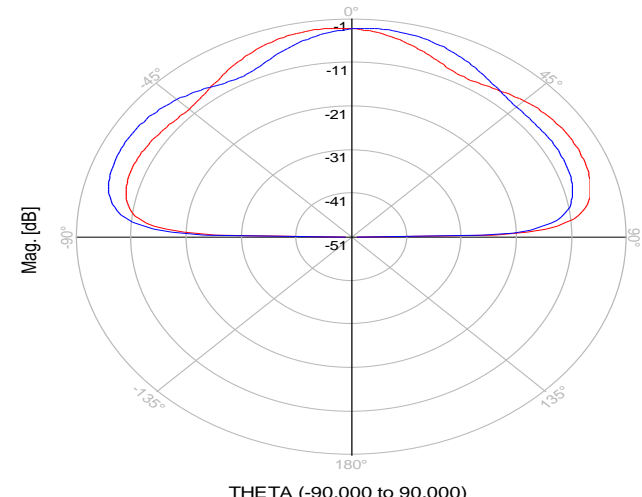

Fig.9. Circular Polarization

\section{CONCLUSION}

The concept of millimeter wave in the mobile communication will launch a revolution in the international cellular plans and that can be achieved by using a steerable directional antenna (phased array antenna). This simple miniaturized antenna design approach towards phased array may help in this 5G future technology. The simulated result analysis gives good performance in terms of different antenna parameters. Furthermore this approach can be used to design a directional / phased array antenna for the millimeter wave mobile communication which will work at frequencies $28 \mathrm{GHz}$ and $38 \mathrm{GHz}$.

\section{REFERENCES}

[1] T. S. Rappaport, J. N. Murdock, and F. Gutierrez, “'State of the art in $60 \mathrm{GHz}$ integrated circuits \& systems for wireless communications," Proc.IEEE, vol. 99, no. 8, pp. 1390_1436, Aug. 2011.

[2] Z. Pi and F. Khan, "An introduction to millimeter-wave mobile broadband systems," IEEE Commun. Mag., vol. 49, no. 6, pp. 101_107, Jun. 2011.

[3] Brajlata Chauhan, Sandeep Vijay and S.C. Gupta "Comparative analysis of Microstrip Patch Antenna using different substrates and observe effect of changing parameter at $5.4 \mathrm{GHz}$ " Word conference CACCS-13, ISBN-978-90-78677-66-6, ISSN-1951-6851 in Atlantis press collaborated with Springer.

[4] A.B. Mutiara, R.Refianti, Rachmansyah "Design of micro strip antenna for wireless Communication at 2.4
GHz" * Journal of Theoretical and Applied Information Technology Vol. 33 Gunadarma university, November 2011.

[5] Hideo Iizuka etal "Millimeter -Wave Microstrip Antenna With High Efficiency For Automotive Radar System" special issue millimeter wave radar for automotive application, R D review of Toyota CRDL vol-37 No.2 2002.

[6] N. J. Kolias, R. C. Compton, J. P. Fitch and D. M. Pozar, Antenna, CRC Press, 2000.

[7] P. Yang, F. Yang, Z. P. Nie, H. J. Zhou, B. Li, and X. F. Tang "Robust Beam-former Using Manifold Separation Technique for Semispherical Conformal Array" IEEE Antennas And Wireless Propagation Letters, Vol. 10, 20111035

[8] R. Iwata and S. Chen, "Mutual Coupling Effects in Microstrip Patch Phased Array Antenna," IEEE Antennas and Propagation Society International Symposium, pp. 1028- 1031, New York, August 2002.

[9] R. F. Harrington, Field Computation by Moment Methods. Piscataway, NJ: IEEE Press, 1993.

[10] A. Chatterjee, L. C. Kempel, and J. L. Volakis, Finite Element Method for Electromagnetic: Antennas, Microwave Circuits, and Scattering Applications. Piscataway, NJ: IEEE Press, 1998.

[11] A. Taove, Computational Electrodynamics: The FiniteDifference Time-Domain Method, 2nd ed. Boston, MA: Artech House, 2000.

[12] A. Bria, F. Gessler, O. Queseth, R. Stridth, M. Unbehaun, J.Wu, J.Zendler, "4-th Generation Wireless Infrastructures: Scenarios andResearch Challenges", IEEE Personal Communications, Vol. 8, No. 6,December 2001.

[13] R. F. Harrington, Field computation by Moment Methods, Maxillan, New York, 1968. [15] T. F. Lai, W. N. Mahadi and N. Soin, "Circular Patch Microstrip Array Antenna for KU band," World Academy of Science, Engineering and Technology. Vol. 48, pp. 298-302, 2008.

[14] Clint, S. P. E. and Myer, J. (2004): $3 G$ Wireless with WiMAX and Wi-Fi: 802.16 and 802.11. United States of America: Mc Grow Hill Companies. 